\title{
Morphological characterisation of the coronary arteries in African sheep (Ovis orientalis). Differential analysis with those of humans and other animal species
}

\author{
F.A. Gómez ${ }^{1 *}$, L.S. Cortés ${ }^{2 *}$, L.E. Ballesteros ${ }^{1 *}$ \\ 'Universidad Industrial de Santander, Bucaramanga, Colombia \\ ¿Universidad Cooperativa de Colombia, Bucaramanga, Colombia \\ [Received: 28 February 2018; Accepted: 2 May 2018]
}

Background: Despite the importance of the coronary system in the African sheep as a possible experimental model, there is little information about this particular vascular system. The objective of this investigation was to characterise morphologically the coronary arteries and their branches in African sheep.

Materials and methods: This descriptive cross-sectional study evaluated the coronary arteries and their branches of 62 hearts of short hair sheep. The right and left coronary ostia were perfused with a semi-synthetic resin (Palatal GP4OL 85\%; styrene 15\%) dyed with mineral red. The morphological characteristics were evaluated using a digital calibrator and the biometrics of the coronary arteries and their branches were registered.

Results: The right coronary artery had a proximal calibre of $2.11 \pm 0.46 \mathrm{~mm}$. The subsinusal interventricular branch ended at the middle third of the homonym sulcus in 19 (30.6\%) specimens. The left coronary artery had a diameter of $5.38 \pm$ $\pm 1.59 \mathrm{~mm}$ and a length of $4.67 \pm 3.32 \mathrm{~mm}$. This artery bifurcated itself in the paraconal interventricular branch and the left circumflex branch in 57 (91.9\%) hearts and trifurcated with an additional left diagonal branch in 5 (8.1\%) specimens. Left coronary artery dominance was observed in 51 (82.3\%) specimens, whereas in 11 (17.7\%) cases the coronary circulation dominance was balanced. Conclusions: Due to the similitude in the features of the coronary arteries between African sheep and humans, this animal model can be proposed for procedural and haemodynamic activities. (Folia Morphol 2019; 78, 1: 63-70)

Key words: sheep, heart, coronary artery disease, dominance

\section{INTRODUCTION}

Few studies have characterised morphometrically the coronary arteries (CA) in sheep and goats; these studies have been limited themselves to describe qualitative aspects and some morphological variants $[12,19,24]$.

The African sheep (Ovis orientalis), known as camuro, pelona or criolla according to the region where it is reared, is native to the Western part of the African continent. African sheep arrived in Colombia introduced to the Atlantic Coast through traders who sold them in Aruba and Curacao. It records the story that from Abyssinia (today Ethiopia) came a nucleus of red African sheep (Ethiopian) in the year 1940 [1].

The right coronary artery (RCA) originates at the upper edge of the right semilunar valve, runs front

Address for correspondence: F.A. Gómez, DMV, MSc, Associate Professor, Universidad Industrial de Santander, Bucaramanga, Colombia, tel: +57 3002004432, e-mail: falegom@uis.edu.co

*These authors contributed equally to the work. 
to back through the atrioventricular sulcus towards the posterior wall of the left ventricle (LV), ending as the right circumflex branch ( $R C \times B)$ (left retroventricular branch in humans). Its branches supply the sinus node and the right atrium and right ventricle (RV) $[12,19]$.

The left coronary artery (LCA) with a short course between the left atrium and the base of the pulmonary trunk divides into the paraconal interventricular branch (PIB) (anterior interventricular branch in humans) and the left circumflex branch (LCXB). The first one descends through the homonymous sulcus, whereas the $L C X B$ runs through the coronary sulcus towards the crux of the heart, where it continues as a subsinusal interventricular branch (SIB) (posterior interventricular branch in humans), which descends through the homonymous sulcus $[12,19]$.

The concept of coronary dominance, widely known in humans, depends on which coronary artery gives origin to the SIB, or which one supplies the greater part of the left posterior ventricular wall $[3,9]$. Right coronary dominance has been reported in pigs, horses, elephants and camels $[8,10,14,30$, $32,33,36]$, while left dominance has been reported in ruminants, donkeys and dogs $[8,27]$. In humans, right coronary dominance has been reported with the highest incidence, within a wide range of $48 \%$ to $90 \%[3,9,21,22,25,34]$.

The presence of myocardial bridges (MB), namely, variable segments of the CA submerged in the ventricular myocardium has not been evaluated in ruminants $[12,19,24]$, whereas in humans, pigs, sheep, goats and camels this finding has been reported within a range of $23 \%$ to $88 \%[2,5,7,17,23]$. In some studies, MB's have been considered as a risk factor for the development of some cardiac conditions $[20,31] . M B$ can induce ischaemia in the areas localised distally to them, due to compression of the blood vessels during the systolic phase of the cardiac cycle, although only a long bridge may have a noticeable impact on the circulation $[2,5,7,17,23]$.

The adequate knowledge of the cardiovascular system of the short hair sheep enriches the concept of comparative anatomy, and allows for proposing this species for experimental physiological models, and for procedural and surgical procedures that use these vascular structures. This study intends to generate significantly important information about the anatomy of the CA of short-haired sheep through the evaluation of fresh hearts; our findings were contrasted with those reported in humans and other animal species.

\section{MATERIALS AND METHODS}

This descriptive cross-sectional study evaluated the characteristics of the CA in 62 hearts of African sheep (Ovis orientalis) male young adult with a weight of $31.7 \pm 6.5 \mathrm{~kg}$ and $10 \pm 2.3$ months of age destined to the slaughterhouse in Bucaramanga, Colombia. The organs were subjected to an exsanguination process for $6 \mathrm{~h}$ in a water source. No samples of females were obtained because of government policies that limit their sacrifice.

After applying a silk patch point around the origin of the $C A$, sealing them, these were perfused with a semi-synthetic resin consisting of a mixture of Palatal ${ }^{\circledR}$ GP40L 85\% $\left(\right.$ BASF $\left.^{\circledR}\right)$, Styrene 15\% (REPSOL $\left.{ }^{\circledR}\right)$, and mineral red dye (Heliogen ${ }^{\circledR}$ ). The specimens were set in a solution of formaldehyde $10 \%$ for $96 \mathrm{~h}$; then, the subepicardial fat adjacent to the coronary beds was released through the impregnation of the anatomical parts in potassium hydroxide $15 \%(\mathrm{KOH})\left(\mathrm{ERCO}^{\circledR}\right)$ for $5 \mathrm{~min}$. Consecutively, the CA and their collateral branches were dissected from their origin to their distal segments; and a digital calliper device (Mitutoyo ${ }^{\circledast}$ ) was used to measure the external diameter of the vessels at $0.5 \mathrm{~cm}$ of their respective origins. The proximal, mid, and distal diameters and its lengths of the CA were recorded, as well as the proximal diameter of its collateral branches; similarly, the distance between the point of finalisation of the SIB and PIB and the cardiac apex was determined. The length of the arteries was determined from the origin to the termination point of its subepicardial course. SIBs or PIBs ending at the upper or mid thirds of the paraconal or subsinusal interventricular sulcus were considered short; those ending at the lower segment of the said sulcus were considered as medium in length, and those reaching the apex or even the anterior aspect of the LV or RV, respectively, were rated as long. The courses and territories irrigated by the branches emerging from the RCA and LCA were determined. The type of coronary dominance was established on the evaluated specimens, according to the criteria described by Schlesinger [34] in humans, adapting it to the international veterinary terminology.

In the right coronary dominance, the RCA supplies the posterior aspect of the RV, gives rise to the SIB and extends beyond the crux of the heart, through its $R C x B$, supplying part of the posterior wall of the LV. In 
Table 1. End of subsinusal interventricular branch (SIB), paraconal interventricular branch (PIB) in homonyms sulcus and end of the first left anterior ventricular branch (LAVB) on the obtuse side of the heart

\begin{tabular}{lccc}
\hline & Total sample SIB & Total sample PIB & Total sample LAVB \\
\hline Upper third & $19(30.6 \%)$ & & $3(11 \%)$ \\
Middle third & $19(30.6 \%)$ & $1(1.6 \%)$ & $10(37 \%)$ \\
Lower third & $18(29 \%)$ & $13(21 \%)$ & $12(44.5 \%)$ \\
Cardiac apex & $6(9.8 \%)$ & $36(58 \%)$ & $2(7.5 \%)$ \\
Posterior surface & & $12(19.4 \%)$ & $27(100 \%)$ \\
Total & $62(100 \%)$ & $62(100 \%)$ & \\
\hline
\end{tabular}

the balanced coronary circulation, the RCA supplies the RV and the posterior aspect of the interventricular septum through the SIB, whereas the LCA supplies the LV ending in the crux of the heart.

In the left coronary dominance, LCXB supplies the posterior aspect of the LV, and ends as the SIB, supplying the posterior segment of the interventricular septum and/or the posterior wall of the RV [21, 25, 34]. Equally, the extent of the left coronary dominance was determined according to the criteria of Didio and Wakefield [13], with a subgroup I when the right and LCAs reach the crux of the heart and end up as parallel posterior interventricular branches; subgroup II, when the LV and the whole of the subsinusal interventricular septum are supplied by the LCA, with only one SIB branch originating from the $\mathrm{LCxB}$; and a subgroup III, when the SIB and the right posterior ventricular branches originate from the LCA to supply the LV, the subsinusal interventricular septum, and part of the RV's posterior wall. We used the International Veterinarian Denominations of 2012 as a reference of the accepted international terminology.

The CA and their branches were assessed for the presence of $\mathrm{MB}$ by determining the segment of the vessel involved, its length, and the thickness of the suprapontine myocardium. A digital camera was used to photograph each of the pieces evaluated.

\section{Statistical analysis}

The continuous variables were analysed using t-test, whereas the discrete variables were analysed using Pearson's $\chi^{2}$ test. The results were evaluated using the statistical programme Epi-Info version 3.5.4. The level of significance used was $p<0.05$. This research was endorsed by the Committee of Ethics of Scientific Research of the Industrial University of Santander, with approval number 05015. The animals were sacrificed for human consumption with a pneumatic gun.

\section{RESULTS}

We evaluated the hearts of 62 short-haired sheep with an average weight of $187.1 \pm 68.1 \mathrm{~g}$. The proximal, middle and distal diameters of the RCA were $2.11 \pm 0.46 \mathrm{~mm} ; 1.75 \pm 0.44 \mathrm{~mm}$ and $1.16 \pm 0.38$ $\mathrm{mm}$, respectively. The SIB ended at the middle third of the homonymous sulcus in 19 (30.6\%) specimens (Table 1). Statistically significant differences were found between the number of SIB's of long and short ending ( $p=0.005)$.

The distance of the SIB with respect to the apex was $36.8 \pm 14.6 \mathrm{~mm}$. The diameters of this branch at its upper, middle and lower segments were $1.94 \pm$ $\pm 0.59 \mathrm{~mm} ; 1.53 \pm 0.51 \mathrm{~mm}$; and $0.98 \pm 0.31 \mathrm{~mm}$, respectively. Anastomoses of the SIB with the PIB were observed in 8 (12.7\%) hearts.

The right conus branch (RCB) was found in 18 (28.6\%) specimens (Fig. 1) with a diameter of $1.32 \pm$ $\pm 0.47 \mathrm{~mm}$. It ended at the conus arteriosus in 11 (61.1\%) specimens, at the upper third of the anterior wall of the RV in $6(33.3 \%)$ specimens and in the middle third in 1 (5.6\%) specimen. In 1 (5.6\%) heart the RCB emerged directly from the right aortic sinus (third coronary artery). An average of $2.73 \pm$ \pm 1.27 ventricular branches emerged from the anterior segment of the RCA.

A right marginal branch (RMB) (Fig. 1) was found in $10(15.9 \%)$ specimens with a diameter of $1.48 \pm$ $0.4 \mathrm{~mm}$. It ended at the middle third of the right margin of the heart in $8(80 \%)$ cases and at the upper third in $2(20 \%)$ specimens.

The sinus node branch (SNB) (Fig. 2) was observed emerging from the RCA at $8.24 \pm 5.1 \mathrm{~mm}$ from its aortic origin. The SNB had a calibre of $1.15 \pm 0.47 \mathrm{~mm}$. The atrioventricular node branch (AVNB), with a calibre of $1.16 \pm 0.8 \mathrm{~mm}$, originated the RCA in 38 $(61.3 \%)$ hearts, whereas in $24(38.7 \%)$ specimens it originated directly from the LCXB. 


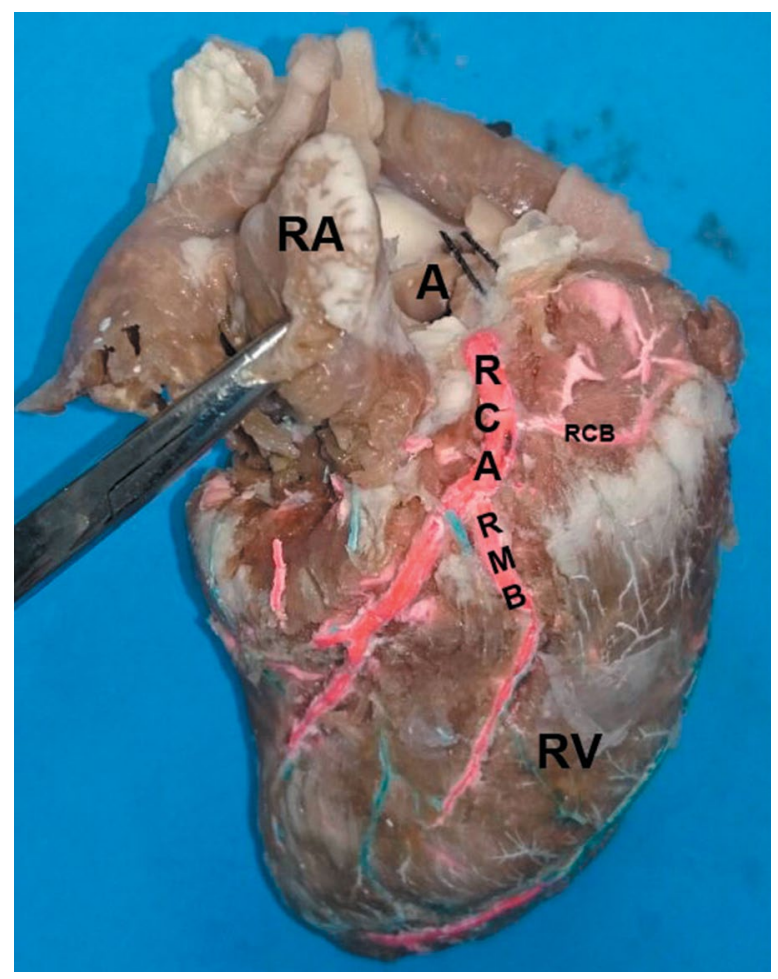

Figure 1. Anterosuperior view of the heart; A - aorta; RA — right atrium; RV — right ventricle; RCA — right coronary artery; RCB right conus branch; RMB — right marginal branch.

The LCA was $5.38 \pm 1.59 \mathrm{~mm}$ in diameter and $4.67 \pm 3.32 \mathrm{~mm}$ in length. This artery bifurcated in PIB and LCXB (Fig. 3) in 57 (91.9\%) hearts and trifurcated in a left diagonal branch (LDB) in 5 (8.1\%) specimens. The LDB was $1.88 \pm 0.67 \mathrm{~mm}$ in diameter and $46.9 \pm 8.84 \mathrm{~mm}$ in length; it ended at the middle third of the obtuse margin of the heart in $100 \%$ of the specimens.

The length of the PIB was very variable ending at the apex in 36 (58\%) cases (Fig. 3), while in 1 case it was short and ended in the middle third of the paraconal interventricular groove (1.6\%) (Table 1). It had a proximal diameter of $3.42 \pm 0.97 \mathrm{~mm}$; mid of $2.23 \pm 0.62$ and distal diameter of $1.41 \pm 0.38$ $\mathrm{mm}$. This branch had on average $1.9 \pm 1.92$ right ventricular branches and $2.6 \pm 1.71$ left ventricular branches. The left conus branch (LCB) (Fig. 3) was present in 21 (33.9\%) specimens, with a diameter of $1.15 \pm 0.45$ and a distance from the origin to the left coronary ostium of $20.97 \pm 6.97 \mathrm{~mm}$.

The first left anterior ventricular branch (LAVB) of the PIB was found in 27 (43.5\%) hearts with a diameter of $1.72 \pm 0.64 \mathrm{~mm}$ and a length of $42.8 \pm 6.55 \mathrm{~mm}$. The distance between its origin and the left coronary ostium was $25.5 \pm 9.8 \mathrm{~mm}$. This branch

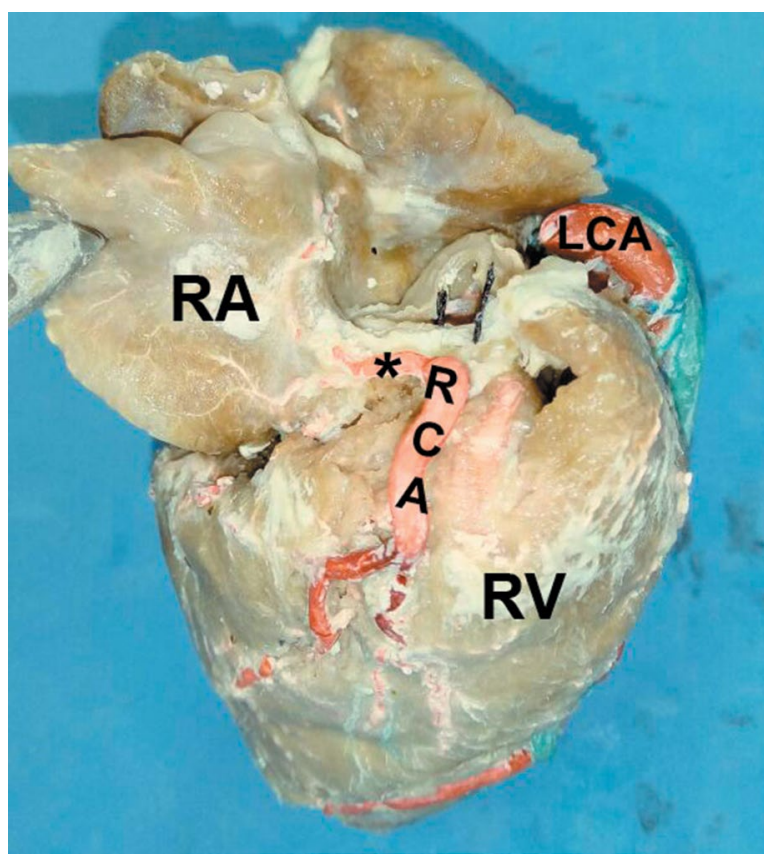

Figure 2. Anterosuperior view of the heart; RA — right atrium; RV — right ventricle; RCA — right coronary artery; LCA — left coronary artery; $\left({ }^{*}\right)-$ sinoatrial node branch.

ended with a higher occurrence (44.5\%) at the lower third of the obtuse margin of the heart (Table 1).

The LCXB ended at the SIS in 48 (77.4\%) specimens (Fig. 4), in 7 (11.3\%) hearts on the posterior aspect of the LV, in $4(6.5 \%)$ specimens in the posterior aspect of the RV, in 2 (3.2\%) hearts at the crux of the heart, whereas in $1(1.6 \%)$ case it ended at the anterior aspect of the LV. Its proximal, middle and distal diameters were $3.29 \pm 0.73 \mathrm{~mm}, 2.83 \pm 0.62 \mathrm{~mm}$ and $1.98 \pm 0.57 \mathrm{~mm}$, respectively. The proximal diameters of the LCXB and the PIB did not present a statistically significant differences $(p=0.33$ ).

The left marginal branch (LMB) (Fig. 3) was found in $37(59.7 \%)$ hearts, ending at the middle third of the obtuse edge of the heart in 21 (56.8\%) specimens, whereas in $9(24.3 \%)$ cases it ended at the lower third, in 5 (13.5\%) specimens at the upper third and in $2(5.4 \%)$ cases at the cardiac apex. Its proximal diameter was $2.28 \pm 0.67 \mathrm{~mm}$ and its distal diameter was of $1.21 \pm 0.4 \mathrm{~mm}$. This branch was $43.42 \pm 17.22 \mathrm{~mm}$ in length, and the distance from the ending point to the apex was $35.9 \pm 12.32 \mathrm{~mm}$.

Left coronary dominance was observed in 51 (82.3\%) specimens, characterised by a SIB that emerges from the LCXB running through the SIS ending in the apex. In 11 (17.7\%) cases the coronary circulation was balanced, with an LCXB ending at the crux of the heart. Left dominance was classified in subgroup II 


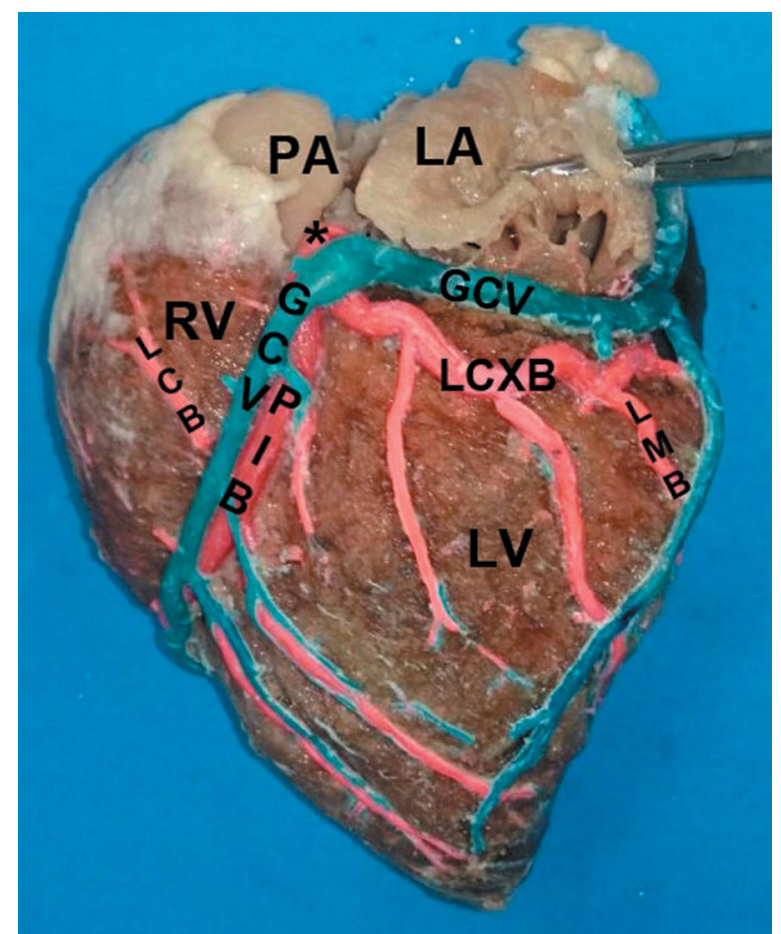

Figure 3. Left surface of the heart; LA — left atrium; LV — left ventricle; $\mathrm{RV}$ - right ventricle; $\mathrm{PA}$ - pulmonary artery; $\mathrm{PIB}$ - paraconal interventricular branch; LCXB - left circumflex branch; LCB — left cone branch; LMB — left marginal branch; GCV — great cardiac vein; $\left({ }^{*}\right)$ - left coronary artery.

in $44(86.3 \%)$ specimens (Fig. 4$)$ and in subgroup III in $7(13.7 \%)$ cases (Fig. 5). No MB was found in the specimens analysed.

\section{DISCUSSION}

The findings obtained in this study about the morphology of the CA in short-haired sheep significantly enrich the existing information, and allows, within a comparative anatomy setting, to compare its characteristics with those of other species such as pigs, camels, donkeys and even humans.

It has been observed in humans, sheep and other animal species that the LCA's calibre is greater than the calibre of the RCA (Table 2). The length of the LCA in sheep has been reported as $6 \mathrm{~mm}[12,24]$. In humans, the length of the LCA is 6 to $15 \mathrm{~mm}$ [4, 26, 37], 3.5 to $5 \mathrm{~mm}$ in pigs [16,33] and of $4 \mathrm{~mm}$ in white rhinos [29]. In humans, pigs and horses the LCA has been shown to be larger in calibre than the RCA, a morphometric trait that is consistent with our findings in short-haired sheep, whereas in the white rhino it has been reported that both CA are similar in size $[4,6,15,16,26,29,33,35,37]$.

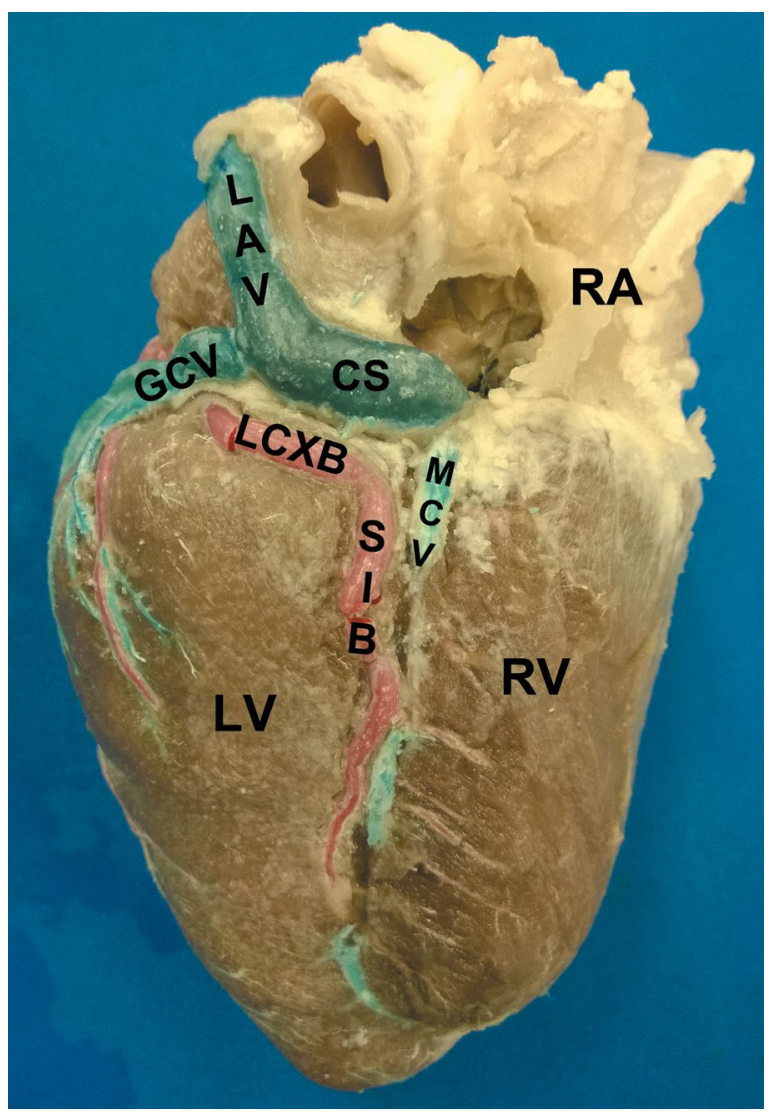

Figure 4. Right surface of the heart. Left coronary dominance, subgroup II; LV — left ventricle; RA — right atrium; RV — right ventricle; LCXB - left circumflex branch; SIB — subsinusal interventricular branch; CS - coronary sinus; GCV — great cardiac vein; MCV — middle cardiac vein; LAV — left azygos vein.

In donkeys, horses, camels and elephants, the LCA has been observed to bifurcate, giving origin to the PIB and the LCXB [10, 12, 14, 27, 36], whereas in the present study there was a trifurcation variant involving the presence of a LDB $(8.1 \%$ of the cases). Similarly, a trifurcation of the LCA has been reported in the white rhino [29]. Some studies in pigs report the bifurcation of the LCA in all of the specimens [11, 33], while in other studies, trifurcation has been reported in $20 \%$ [16]. In humans, bifurcation of the LCA has been reported in $40 \%$ to $70 \%$, trifurcation in $9 \%$ to $55 \%$ and tetrafurcation in $5 \%$ to $7 \%[4,26]$.

The calibre of the SIB has been reported having a range of 1 to $2.75 \mathrm{~mm}$ in sheep, humans, pigs, white rhino, goats and horses (Table 2) [6, 12, 15, 24, 29, 35, 37]. The SIB has been reported to end mainly at the apex in donkeys, elephants, camels, white rhino and humans $[6,10,14,21,27,29]$, a finding that differs with ours, which in turn is consistent with the reports from horses 
and pigs, which note the SIB as ending at the middle third of the subsinusal interventricular groove $[8,15]$.

The presence of anastomoses between the terminal branches of the SIB and the PIB was observed in $12.7 \%$ of the hearts in this study, it is a relevant morphological expression for its protective role of coronary blood supply. The distal segment of the PIB, after surpassing the cardiac apex, branches out in the lower segment of the diaphragmatic aspect and

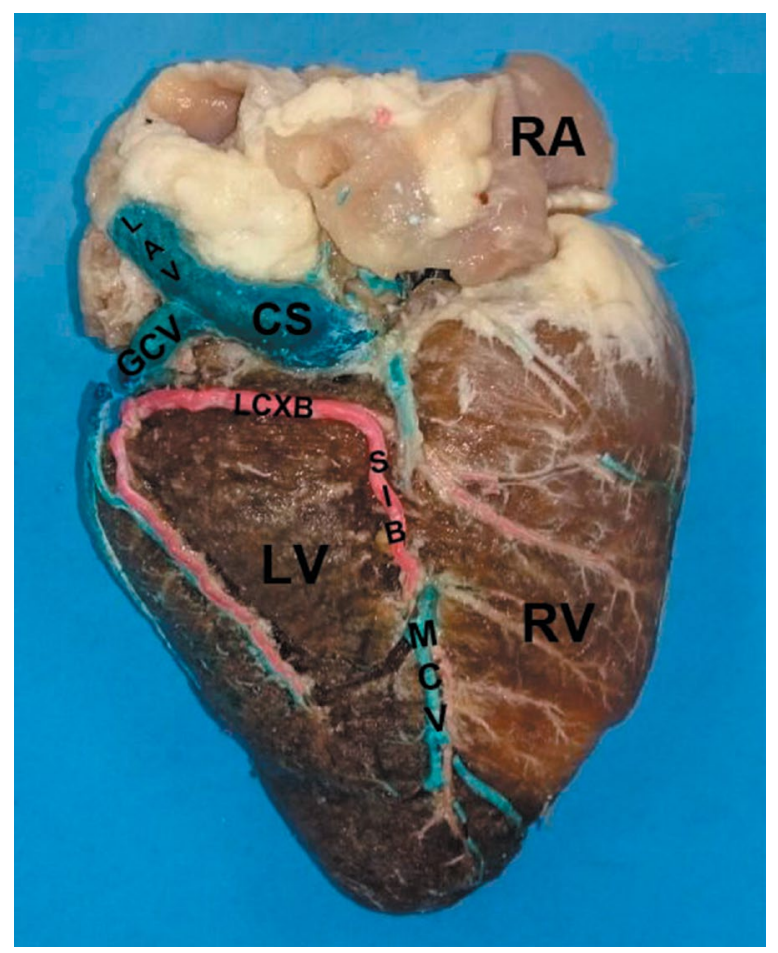

Figure 5. Right surface of the heart. Left coronary dominance, subgroup III; LV — left ventricle; RA — right atrium; RV — right ventricle; LCXB - left circumflex branch; SIB — subsinusal interventricular branch; CS - coronary sinus; GCV — great cardiac vein; MCV middle cardiac vein; LAV — left azygos vein. irrigates the area not reached by the SIB. In humans, this anatomical feature should be accounted for in determining the arterial structure that, when obstructed, causes the infarction of the lower segment of the posterior wall of the heart [4].

In the present study, similarity was found that, in humans the calibre of the PIB is lower than in the pig and higher than in the white rhino (Table 2) $[4,16,29]$.

The observation of most PIB ending at the cardiac apex (58\%), as observed in this work, is consistent with what has been reported in elephants, rhino, pigs and humans $[4,10,16,27,29,33]$. In humans, short-haired sheep and pigs, the PIB has a larger calibre of the SIB.

According to the present study, the LCXB has been reported to be long and to end mainly at the SIS in elephants [10], whereas in camels, pigs and humans it has been reported as ending mainly at the posterior aspect of the $\operatorname{LV}[4,11,16,33]$. Ozgel et al. [27] points out that the LCXB is short and ends mainly as LMB in donkeys. In sheep, humans (retroventricular branch), pigs, dogs and bovines the presence of a right circumflex branch has been observed $[6,12,15]$, which was not observed in the specimens of this study.

In humans, pigs, donkeys and camels it has been reported a higher incidence of the RCB ending at the arteriosus cone $[6,14,15,27]$, an anatomical trait that is consistent with our findings (61.1\%). Similarly, the anastomosis of the RCB with the left branch of the cone was not observed in donkeys, horses, camels, elephants, and pigs [10, 14, 15, 27, 33].

The RCB originating from the right aortic sinus (third coronary artery) is an uncommon feature of the coronary circulation that has been reported in a small number of observations for some animal species, such

Table 2. Morphometric of the coronary arteries and their branches in humans and some animal species

\begin{tabular}{|c|c|c|c|c|c|}
\hline Species & Author, year & Calibre RCA [mm] & Calibre LCA [mm] & Calibre SIB [mm] & Calibre PIB [mm] \\
\hline Human & $\begin{array}{l}\text { Zindrou et al., 2006; } \\
\text { Ballesteros et al., } 2011\end{array}$ & $3.4-4.1$ & $3.58-5$ & 2.04 & $2.94-4$ \\
\hline Sheep & Deepak and Rao, 2010 & 1 & 2 & 1 & 3 \\
\hline Goat & $\begin{array}{l}\text { Lipovetsky et al, 1983; } \\
\text { Deepak and Rao, } 2010\end{array}$ & 1.8 & 2.25 & 2 & 2 \\
\hline White Rhino & Perez and Lima, 2010 & 1.7 & 1.7 & 1.2 & 1.7 \\
\hline Pig & $\begin{array}{l}\text { Gómez and Ballesteros, } \\
2013 \text { and } 2014\end{array}$ & 3.85 & 6.98 & 2.75 & 4.06 \\
\hline Horse & Thüroff et al., 1984 & 8.91 & 8.91 & & \\
\hline African sheep & Present study & 2.11 & 5.38 & 1.94 & 3.42 \\
\hline
\end{tabular}

LCA — left coronary artery; PIB — paraconal interventricular branch; RCA — right coronary artery; SIB — subsinusal interventricular branch 
Table 3. Coronary dominance in humans and some animal species

\begin{tabular}{|c|c|c|c|c|}
\hline Species & Author, year & Right dominance & Left dominance & Balanced circulation \\
\hline Human & Nerantzis et al, 1996; Ballesteros et al., 2007 & $48-90 \%$ & $5-20 \%$ & $10-20 \%$ \\
\hline Sheep & $\begin{array}{l}\text { Bertho and Gagnon, 1964; Deepak and Rao, 2010; } \\
\text { Pérez and Lima, } 2010\end{array}$ & & $\mathrm{X}$ & \\
\hline Goat & $\begin{array}{l}\text { Bertho and Gagnon, 1964; Deepak and Rao, 2010; } \\
\text { Pérez and Lima, } 2010\end{array}$ & & $\mathrm{X}$ & \\
\hline White Rhino & Pérez and Lima, 2010 & $X$ & & \\
\hline Pig & Sahni et al, 2008; Gómez and Ballesteros, 2015 & $66.5 \%$ & & $33.5 \%$ \\
\hline Horse & Bertho and Gagnon, 1964 & $X$ & & \\
\hline Donkeys & Ozgel et al., 2004 & & $x$ & \\
\hline Camels & Ghazi and Tadjalli, 1993 & $x$ & & \\
\hline Dog & $\begin{array}{l}\text { Bertho and Gagnon, 1964; Deepak and Rao, 2010; } \\
\text { Pérez and Lima, } 2010\end{array}$ & & $x$ & \\
\hline Elephants & Cave, 1936 & $X$ & & \\
\hline African sheep & Present study & & $82.3 \%$ & $11.7 \%$ \\
\hline
\end{tabular}

as elephants and pigs $[10,15,33]$, which is consistent with our findings (5.6\%). This feature is widely observed in humans in a range of $25 \%$ to $35 \%$ [6, 22].

The AVNB originating from the RCxB has been observed in camels and pigs in a range of $85 \%$ to $100 \%[11,14,15,33]$, whereas in the present study it originated from branches of the RCA in $60.3 \%$ and directly of the LCXB in $39.7 \%$ of the cases.

In humans, this morphological trait is reported to originate from the RCxB within a range of between $85 \%$ and $92 \%$ and from $8 \%$ to $15 \%$ from the LCXB $[6,11,33]$.

Previous studies conducted in pigs have reported the SNB as emerging from the RCA in all of their specimens $[11,15]$, an anatomical trait that is consistent with that observed in our study. In humans, the SNB has been reported as originating from the RCA in 50 to $79 \%$ of the cases, from the LCXB in 30 to $45 \%$ of the cases, and from both arteries in $3 \%$ to $7 \%$ of the cases $[6,28]$.

In donkeys, pigs and humans the LMB has been reported as ending mainly at the upper third of the obtuse margin of the heart $[4,16,27]$, whereas we have seen it ending at the middle third in the majority of our specimens of this study.

Coronary dominance refers to the coronary artery supplying greater territory in the heart and, depending on the species, right or left coronary dominances are found, as well as balanced circulations. In the present study and in previous reports it was determined what type of dominance the human and different animal species had (Table 3) [3, 8-10, 12, 14, $21,25,27,29,30,32,33]$.

\section{CONCLUSIONS}

This qualitative and quantitative study of CA and its branches in African sheep provides new knowledge for the anatomy of the species.

Unlike most species, there was no presence of an RCxB.

The LCXB was predominantly long and ended at the SIS, which confirms the left coronary dominance pattern described in ruminants. Given the relative similarity of CA morphological characteristics expressed in left coronary dominance and in the balanced circulation, predominant in the African sheep and present in 25-35\% of humans, together with the easy and economical access to this animal species and the simple locative scenarios required, allows us to postulate this animal model for haemodynamic and procedural studies.

\section{Acknowledgements}

To "Frigorífico Caprinos Alvarez", Bucaramanga, Colombia, for the specimen donation enabling this research and to the undergraduate student Yesid Osorio Lizarazo, for his active participation in the preparation of the specimens for the study.

\section{REFERENCES}

1. Arcos JC, Romero H, Vanegas MA, et al. Ovinos colombianos de pelo corto. CORPOICA, Ministerio de Agricultura y Desarrollo Rural, Ibagué - Colombia. 2002: 9.

2. Babiker AM, Taha AM. Myocardial bridges of the heart of the dromedary camel (Camelus dromedarius). U of KJ Vet. Med \& Anim Pro. 2013; 4: 90-105.

3. Ballesteros L, Corzo E, Saldarriaga B, et al. Determinación de la Dominancia Coronaria en Población Mestiza Colom- 
biana: Un Estudio Anatómico Directo. Int J Morphol. 2007; 25(3), doi: 10.4067/s0717-95022007000300003.

4. Ballesteros LE, Ramirez LM. Morphological expression of the left coronary artery: a direct anatomical study. Folia Morphol. 2008; 67(2): 135-142, indexed in Pubmed: 18521813.

5. Ballesteros LE, Ramírez LM, Saldarriaga B. Morphological description and clinical implications of myocardial bridges: an anatomical study in Colombians. Arq Bras Cardiol. 2009; 92(4): 256-262, indexed in Pubmed: 19565132.

6. Ballesteros LE, Ramirez LM, Quintero ID. Right coronary artery anatomy: anatomical and morphometric analysis. Rev Bras Cir Cardiovasc. 2011; 26(2): 230-237, indexed in Pubmed: 21894413.

7. Berg R. [On the presence of myocardial bridges over the coronary vessels in swine (Sus scrofa domesticus)]. Anat Anz. 1963; 112: 25-31, indexed in Pubmed: 13970616.

8. Bertho $E$, Gagnon $G$. A comparative study in three dimension of the blood supply of the normal interventricular septum in human, canine, bovine, procine, ovine and equine heart. Dis Chest. 1964; 46: 251-262, indexed in Pubmed: 14206348.

9. Cavalcanti JS, de Lucena Oliveira M, Pais e Melo AV, et al. [Anatomic variations of the coronary arteries]. Arq Bras Cardiol. 1995; 65(6): 489-492, indexed in Pubmed: 8731301.

10. Cave AJ. On the cardiac arteries of the asiatic elephant. J Anat. 1936; 71(Pt 1): 124-127, indexed in Pubmed: 17104622.

11. Crick SJ, Sheppard MN, Ho SY, et al. Anatomy of the pig heart: comparisons with normal human cardiac structure. J Anat. 1998; 193 ( Pt 1): 105-119, indexed in Pubmed: 9758141.

12. Deepak S, Rao K. Comparative anatomy of the coronary arteries in case of humans with other mammals. Anatomica Karnataka. 2010; 4: 35-41.

13. Didio $\sqcup$, Wakefield TW. Coronary arterial predominance or balance on the surface of the human cardiac ventricles. Anat Anz. 1975; 137(1-2): 147-158, indexed in Pubmed: 1163806.

14. Ghazi SR, Tadjalli M. Coronary arterial anatomy of the onehumped camel (Camelus dromedarius). Vet Res Commun. 1993; 17(3): 163-170, indexed in Pubmed: 8284892.

15. Gómez FA, Ballesteros LE. Anatomic study of the right coronary artery in pigs: feature review in comparison with the human artery. Int J Morphol. 2013; 31(4): 1289-1296, doi: 10.4067/s0717-95022013000400023.

16. Gómez FA, Ballesteros LE. Morphologic expression of the left coronary artery in pigs. An approach in relation to human heart. Rev Bras Cir Cardiovasc. 2014; 29(2): 214-220, indexed in Pubmed: 25140471.

17. Gómez FA, Ballesteros LE. Characterization of myocardial bridges in pigs: a comparative anatomical analysis with the human heart. Folia Morphol. 2015; 74: 395-398.

18. Gómez FA, Ballesteros LE. Evaluation of coronary dominance in pigs; a comparative study with findings in human hearts. Arq Bras Med Vet Zootec. 2015; 67(3): 783-789, doi: 10.1590/1678-4162-6637.

19. González ME, Rojo C. Anatomía Veterinaria. Estudio del corazón. Morfología. Anatomía comparada. Dependencias cavitarias, valvulares y vasculares. Reduca. 2010; 2: 1-20.

20. Gow RM. Myocardial bridging: does it cause sudden death? Card Electrophysiol Rev. 2002; 6(1-2): 112-114, indexed in Pubmed: 11984030.
21. James TN. Anatomy of the coronary arteries in health and disease. Circulation. 1965; 32(6): 1020-1033, indexed in Pubmed: 5846099.

22. Kalpana RA. study on principal branches of coronary arteries in humans. J Anat Soc India. 2003; 52: 137-140.

23. Kosiński A, Grzybiak M, Kozłowski D. Distribution of myocardial bridges in domestic pig. Pol J Vet Sci. 2010; 13(4): 689-693, indexed in Pubmed: 21370748.

24. Lipovetsky G, Fenoglio JJ, Gieger M, et al. Coronary artery anatomy of the goat. Artif Organs. 1983; 7(2): 238-245, indexed in Pubmed: 6870600.

25. Nerantzis CE, Papachristos JC, Gribizi JE, et al. Functional dominance of the right coronary artery: incidence in the human heart. Clin Anat. 1996; 9(1): 10-13, doi: 10.1002/ (SICI) 1098-2353(1996)9:1<10::AID-CA2>3.0.CO;2-3, indexed in Pubmed: 8838273.

26. Ortale J, Filho JM, Paccola A, et al. Anatomia dos ramos lateral, diagonal e ântero-superior no ventrículo esquerdo do coração humano. Rev Bras Cir Cardiovasc. 2005; 20(2): 149-158, doi: 10.1590/s0102-76382005000200010.

27. Ozgel O, Haligur AC, Dursun N, et al. The macroanatomy of coronary arteries in donkeys (Equus asinus L.). Anat Histol Embryol. 2004; 33(5): 278-283, doi: 10.1111/j.14390264.2004.00548.x, indexed in Pubmed: 15352880.

28. Pejković B, Krajnc I, Anderhuber F, et al. Anatomical aspects of the arterial blood supply to the sinoatrial and atrioventricular nodes of the human heart. J Int Med Res. 2008; 36(4): 691-698, doi: 10.1177/1473230008036004 10, indexed in Pubmed: 18652764.

29. Pérez W, Lima M. Distribución de las Arterias Coronarias en el Rinoceronte Blanco (Ceratotherium simum). Int J Morphol. 2010; 28(3): 811-814, doi: 10.4067/s071795022010000300023.

30. Rawlings CA. Coronary arterial anatomy of the small pony. Am J Vet Res. 1977; 38(7): 1031-1035, indexed in Pubmed: 883710.

31. Rychter K, Salanitri J, Edelman RR. Multifocal coronary artery myocardial bridging involving the right coronary and left anterior descending arteries detected by ECG-gated 64 slice multidetector CT coronary angiography. Int J Cardiovasc Imaging. 2006; 22(5): 713-717, doi: 10.1007/ s10554-006-9086-7, indexed in Pubmed: 16625313.

32. Sabathie LG, Pianetto MB. Las arterias coronarias del caballo. Rev Argent Cardiol. 1941; 8: 184.

33. Sahni $D$, Kaur GD, Jit $H$, et al. Anatomy and distribution of coronary arteries in pig in comparison with man. Indian J Med Res. 2008; 127(6): 564-570, indexed in Pubmed: 18765875.

34. Schlesinger MJ. Relation of anatomic pattern to pathologic conditions of the coronary arteries. Arch Pathol. 1940; 30: 403-415.

35. Thüroff JW, Hort W, Lichti H. Diameter of coronary arteries in 36 species of mammalian from mouse to giraffe. Basic Res Cardiol. 1984; 79(2): 199-206, indexed in Pubmed: 6743189.

36. Yuan G, Ma J, Ye W, et al. Macroanatomy of coronary arteries in Bactrian camel (Camelus bactrianus). Vet Res Commun. 2009; 33(4): 367-377, doi: 10.1007/s11259008-9185-0, indexed in Pubmed: 19011985.

37. Zindrou D, Taylor KM, Bagger JP. Coronary artery size and disease in UK South Asian and Caucasian men. Eur J Cardiothorac Surg. 2006; 29(4): 492-495, doi: 10.1016/j. ejcts.2006.01.008, indexed in Pubmed: 16473514. 